\title{
PERJUANGAN KELAS PENGESAHAN RUU PENGHAPUSAN KEKERASAN SEKSUAL
}

\section{Nikodemus Niko', Atem Atem ${ }^{2}$, Alif Alfi Syahrin ${ }^{3}$, Alfin Dwi Rahmawan ${ }^{4}$, Anggi Mardiana ${ }^{5}$}

\author{
1)2)5) Universitas Padjadjaran; 3) Universitas Pendidikan Indonesia; \\ 4) Universitas Bangka Belitung \\ nikodemus15001@mail.unpad.ac.id
}

Received: 24 May 2020 | Reviewed: 29 June 2020 | Accepted: 28 July 2020

\begin{abstract}
ABSTRAK
Tulisan ini ingin menempatkan gejolak perjuangan kelas-pemikiran Karl Marx-sebagai bahan kajian analisis kritis dalam melihat upaya perjuangan pengesahan RUU Penghapusan Kekerasan Seksual di Indonesia, utamanya dalam aksi mahasiswa bersama dengan rakyat pada gerakan \#GejayanMemanggil, \#RakyatGugatNegara dan aksi lainnya di berbagai wilayah di Indonesia. Ide utama dari esai ini adalah bahwa teori kelas Marx hadir berdasarkan filosofi pemahaman terhadap fenomena sosial; adanya pembagian kelas pada masyarakat itu sendiri. Pada studi ini dilihat adalah kelas penguasa (pemerintah; negara) dan kelas rakyat biasa. Marx berkeyakinan bahwa inklusivitas dalam masyarakat hanya dapat tercapai melalui perjuangan kelas. Tulisan ini menggunakan jenis metode penelitian kualitatif deskriptif dengan pendekatan kajian pustaka. Eksplorasi data sekunder dalam tulisan ini didapatkan melalui penelusuran tulisan ilmiah dan tulisan populer seperti jurnal, tulisan di koran, media daring dan buku yang terkait dengan tema dalam tulisan ini. Berdasarkan analisis data, temuan dalam kajian ini bahwa pada konteks perjuangan perempuan (secara organisasi dan individu) dan orang-orang yang memiliki kepedulian pada kekerasan seksual di Indonesia, menghadapi tantangan perjuangan kelas perempuan dalam mendesak pengesahan RUU penghapusan kekerasan seksual menjadi Undang-Undang
\end{abstract}

Kata Kunci: Karl Marx, Perjuangan Kelas, Kekerasan Seksual, RUU Penghapusan Kekerasan Seksual

Korespondensi:

Universitas Padjadjaran

Jl. Raya Bandung Sumedang KM.21, Hegarmanah, Kecamatan. Jatinangor, 


\begin{abstract}
This paper put the turmoil of the class struggle - Karl Marx's thoughts - as a critical analysis study given the efforts to struggle for the ratification of sexual violence in Indonesia, primarily in student action along with people on \#GejayanMemanggil, \#RakyatGugatNegara and other actions in various regions in Indonesia. The main idea of this essay is that Marx's class theory is presently based on the philosophy of understanding the social phenomena; of class division in the community. In this study, we were seen that the ruling class (government; state) and the regular folk class. Karl Marx's thought was based on the presuppositions that the main actors in society were social classes, how human alienation was the result of a class's suppression by other classes. This paper uses a type of descriptive qualitative research method with a library review approach. The exploration of secondary data in this paper is obtained through the search of popular scientific papers such as journals, newspapers, online media, and books. Based on data analysis, the findings in this study that in the context of women's struggle (by organization and individual) and those who have concern for sexual violence in Indonesia, face the challenge of the women's class struggle in urging the ratification of the BILL to remove sexual violence into law
\end{abstract}

Keywords: Karl Marx, class struggles, sexual violence, the BILL of elimination of sexual violence

\title{
PENDAHULUAN
}

Fenomena kekerasan seksual di Indonesia seperti halnya fenomena gunung es. Kekerasaan seksual terutama pada perempuan dan anak selalu berada pada peringkat tertinggi dengan total kasus yang selalu mengalami kenaikan setiap tahunnya. Berdasarkan catatan tahunan (CATAHU) Komisi Nasional Anti Kekerasan Terhadap Perempuan (Komnas Perempuan, 2019) Kekerasan yang banyak terjadi yakni kekerasan dalam rumah tangga atau KDRT. Kekerasan dalam ranah personal ini pada tahun 2019 saja mencapai angka 71\% (9.637) kasus. Pada ranah KDRT kekerasan seksual menempati posisi kedua setelah kekerasan fisik dengan banyak 2.988 kasus atau sebanyak 31\%. Kekerasan seksual di ranah personal berdasarkan catatan tahunan Komnas Perempuan (2019) menyebutkan banyak dilakukan oleh pacar sedangkan untuk KDRT berada di peringkat kedua terbesar yaitu dilakukan oleh ayah kandung, paman, suami, sepupu dan saudara/kerabat.

Selain melihat kekerasan seksual di ranah personal, banyak kasus-kasus kekerasan perempuan yang terjadi di ranah publik atau komunitas. Tercatat 3,915 kasus (64\%) kekerasan 
perempuan di ranah publik adalah kekerasan seksual yaitu pencabulan 1.136 kasus, perkosaan 762 kasus, dan pelecehan seksual 394 kasus. Komnas perempuan (2019) mencatat pelaku kekerasan seksual di ranah publik yang dikeluarkan catatan tahunan pada peringkat pertama dilakukan oleh tetangga. Kemudian yang kedua disusul oleh teman sebanyak 506 kasus, orang lain 465 kasus, orang tidak dikenal 452, dan guru 125 kasus. Tantangan besar sebenarnya untuk menciptakan ruang aman bagi perempuan terhadap kekerasan seksual (lihat Wariyatun, 2019), dan percepatan pengesahan RUU Penghapusan Kekerasan Seksual adalah jalan bagi perempuan mendapatkan ruang aman.

Berdasarkan data-data tersebut Indonesia bukanlah negara yang ramah terhadap warganya mengenai kekerasan seksual. Contoh kasus yang mencuat ke ranah hukum seperti kasus Baiq Nuril dan Agni. Mereka adalah korban kekerasan seksual tetapi juga menjadi korban dari hukum yang berlaku di Indonesia. Hukum Indonesia yang tidak ramah bagi korban kekerasan dan pelecehan seksual. Movement yang dilakukan di Indonesia atas pengesahan RUU Penghapusan Kekerasan Seksual ini juga terjadi pada negara-negara maju (termasuk negara-negara di Asia), bahkan jauh sebelum di Indonesia (lihat. Baker \& Bevacqua 2017); Levine, 2017; Aktar, 2019; Lin \& Yang, 2019; Sovann, 2019).

Kasus lain pada kekerasan seksual yang terjadi selama bertahun-tahun seperti ini biasanya banyak dilakukan oleh orang-orang terdekat korban seperti keluarga hingga teman bermain. Seperti halnya kasus di Kulon Progo Daerah Istimewa Yogyakarta, bocah yang berusia 15 tahun yang diperkosa oleh ayah tirinya selama bertahun-tahun (Dewantara, 2020). Korban mengalami perkosaan oleh ayah tirinya sejak berumur 13 tahun, dari April 2014 hingga awal tahun 2019. Korban mengalami depresi yang sangat mendalam dan menanggung beban psikis yang luar biasa selama bertahun-tahun. Artinya bahwa banyak sekali efek serius yang dihadapi korban kekerasan seksual (lihat Basile \& Smith, 2011); Guruge, Roche \& Catallo, 2012); Cripps \& Stermac 2018).

Kemudian, kasus Agni seorang mahasiswi salah satu universitas terkemuka di pulau Jawa yang juga menjadi korban kekerasan seksual ketika menjalankan kuliah kerja nyata (KKN) bersama dengan pelaku berinisial HS. Selama lebih dari dua tahun sejak terjadinya pelecehan seksual di tahun 2017 hingga berakhir damai Agni berusaha mencari keadilan 
terhadap kasus yang menimpanya. Walaupun kasus berakhir damai tetapi tidak ada kesepakatan bahwa kasus Agni masuk ke dalam kasus kekerasan seksual. Selain kedua kasus tersebut, masih banyak lagi kekerasan yang terjadi di ranah publik, terutama kekerasan seksual yang terjadi di tampat kerja. Berdasarkan survei yang dilakukan oleh never okay dalam rentang 19 November-9 Desember 2018 sebanyak 1.240 responden mengalami pelecehan seksual di tempat kerja yang tersebar di 34 provinsi di Indonesia (Never Okay Project, 2018). Hal ini mengisyaratkan bahwa Indonesia perlunya aturan tentang perlindungan pekerja dari pelecehan seksual di tempat kerja. Karena mengingat hanya Indonesia saja yang tidak memiliki aturan perlindungan pekerja dari kekerasan seksual di tempat kerja.

Kekerasan seksual yang marak terjadi ini seakan-akan menjadi fenomena gunung es yang sulit sekali dipecahkan. Dari sekian banyak data yang terlapor dari kasus kekerasan seksual banyak juga kasus kekerasan seksual yang tidak terdata atau teridentifikasi karena korban enggan untuk melapor. Kemudian, ada kesalahpahaman antara pemaknaan seksualitas dan perkosaan (Niko \& Rahmawan, 2020) yang membuat kompleksitas. Hal ini dikarena terdapat faktor psikis korban ketika korban harus melaporkan kasus tersebut. Keluar dari siklus kekerasan seksual sangatlah tidak mudah. Bahkan jika kita melihat kekerasan seksual yang diterima oleh korban banyak yang sudah terjadi bertahun-tahun lamanya. Kenapa hal itu bisa terjadi? Bisa saja korban merasa takut untuk melapor karena dapat membuka luka lama yang diterima oleh korban. Atau bisa jadi karena adanya ancaman-ancaman oleh pelaku kejahatan seksual.

Kekerasan seksual dapat terjadi dimana saja dan oleh siapa saja. Korban kekerasan seksual menanggung beban berlapis dalam kehidupannya. Negara seharusnya menjamin rasa aman dan perlindungan kepada setiap warganya mengenai kekerasan seksual yang sewaktuwaktu dapat terjadi oleh setiap orang, dan juga negara harus hadir dalam untuk korban kekerasan seksual. Penyuaraan terus menerus dilakukan, bahkan hingga hari ini promosi dalam SDGs (Sustainable Development Goals) nomor 5 yang menyantumkan promosi keadilan gender dan pemberdayaan perempuan (Bayeh, 2016; Devi, 2017; Garcia-Moreno \& Amin, 2019; Moyo \& Dhliwayo, 2019). 
Selama ini, pelaku kejahatan seksual dapat lolos dari jeratan hukum karena belum ada undang-undang yang secara spesifik mengatur tentang kekerasan seksual secara asas legalitas. Oleh karena itu, begitu pentingnya RUU Penghapusan Kekerasan Seksual harus di sahkan sebagai bentuk kepedulian negara terhadap kasus kekerasan seksual yang masih marak terjadi di Indonesia. Tulisan ini mencoba untuk menyelami makna perjuangan kelas atas pendesakan pengesahan RUU Penghapusan Kekerasan Seksual di Indonesia dengan perspektif perjuangan kelas Marx.

\section{KAJIAN TEORI}

Marx dan gerakan sosial pada dasarnya melawan kapitalisme (Barker, et al). Karl Marx beranggapan bahwa pelaku utama dalam masyarakat adalah kelas-kelas sosial. Artinya bahwa kelas yang kuat dan kelas yang lemah dalam masyarakat memunculkan gerakan-gerakan sosial. Kita telah melihat bahwa keterasingan manusia adalah hasil penindasan satu kelas ke kelas lainnya. Emansipasi dari keterasingan itu hanya dapat tercapai melalui perjuangan kelas (Suseno, 2016). Marx beranggapan jika masyarakat ingin terbebas dari penindasan dan keterasingan maka masyarakat harus melakukan sebuah revolusi, yakni perjuangan kelas (Coburn, 2016; Berberoglu, 2018).

Menurut Karl Marx masyarakat terdiri dari dua kelas yang didasarkan pada kepemilikan sarana dan alat produksi yaitu kelas borjuis dan proletar. Kelas proletar adalah kelas yang tidak memiliki sarana dan alat produksi (Setiadi \& Kolip, 2011). Kelas sosial terdiri dari sejumlah orang yang memiliki status sosial baik yang diperoleh dari kelahiran (ascribed status), perjuangan untuk meraih status sosial (aschieved status), dan karena pemberian (assigned status). Adanya kelas dalam masyarakat ini memunculkan konflik di dalam masyarakat itu sendiri. Dalam teori konflik sosial memandang antar elemen sosial/kelas memiliki kepentingan yang berbeda, sementara pandangan teori struktur fungsional menempatkan elemen sosial saling mendukung kehidupan sistem sosial.

Perjuangan kelas yang Marx maksudkan adalah perlawanan terorganisir yang berasal dari kaum kelas proletar melawan kaum kelas bourjouis. Gagasan analisis kelas dalam model Marxis mengandung sejumlah ambisi yang sangat besar yaitu melandasi prinsip 
pengorganisasian yang khas bagi analisis sosial-politik. Bahwasannya Marx menegaskan kesadaran kelas ini harus dibangkitkan dari 'luar". Disamping itu, gagasan tersebut juga beramisi untuk menyediakan metode terbaik demi memberikan pemaknaan dan koherensi teoritis dan empiris bagi luasnya pengakumulasian data apa pun yang mengisi rekaman sejarah dari kehidupan masyarakat (Martinez, 2017). Titik berangkat analisis-kelas Marxisme yaitu melalui Communist Manifesto yang didalamnya Marx dan Engels mendeklarasikan bahwa sejarah dari semua bentuk masyarakat yang eksis sampai sekarang adalah sejarah tentang perjuangan kelas. Gerakan perjuangan kelas dalam pandangan Marxist pada dasarnya adalah collective action (tindakan kolektif) yang muncul sebagai reaksi atas ketertekanan kaum proletar oleh kelas penguasa.

Teori kelas Marx menegaskan bahwa kesadaran kelas akan tumbuh kolektive sebagai akibat dari tekanan kelas borjuis (Berberoglu, 2018). Meskipun pendekatan teoritis Marx secara keseluruhannya dapat diterapkan pada tahap sejarah yang mana perhatian utamanya adalah pada tahap masyarakat kapitalis — perkembangannya sejak semula di akhir masa feodal, ketegangan-ketegangan dan kontradiksi internalnya, hingga akhirnya bubar dan berubah menjadi masyarakat komunis yang akan datang melalui kegiatan revolusioner kelas proletar.

Menurut Marx, kontradiksi dasar dalam struktur masyarakat kapitalis sudah mencapai puncaknya dalam krisis ekonomi; dengan adanya krisis ekonomi itu sudah pasti sistem kapitalis akan menderita. Kaum kapitalis bersaing satu sama lain untuk memperoleh keuntungan, kelebihan produksi yang dihasilkan merupakan dasar untuk memperoleh keuntungan. Hal ini memunculkan respon yang massive di kalangan kaum buruh di tingkat global. Marx tidak menyajikan suatu perencanaan terperinci mengenai masyarakat post-kapitalis, tetapi dia membayangkan suatu masyarakat dimana keuntungan produksi yang dihasilkan oleh kapitalisme akan dimiliki secara kolektif, daripada secara pribadi. Marx memandang bahwa hal ini akan membebaskan individu dari keharusan menggunakan semua waktunya untuk lebih mengembangkan kemampuan-kemampuan mereka sebagai manusia.

Pada tingkat global munculnya keadaan krisis ekonomi, memungkinkan munculnya kesadaran kelas yang lebih kuat di pihak kaum proletar. Kemungkinan-kemungkinan ini diimbangi dengan kompetisi antara kaum buruh dengan kaum proletar, yang mana kaum buruh 
akan mendapatkan keuntungan karena pekerjaan yang langka dan upah yang meniingkat. Mengatasi persaingan ini yaitu dengan mengembangkan kesadaran kelas. Kesadaran yang dibangun yaitu menuntut bahwa kaum buruh harus senantiasa mendapatkan jalan untuk proses sejarah, dimana mereka terlibat didalamnya. Pada fenomena nasional yang diangkat dalam tulisan ini yaitu dinamika kolektif yang terjadi terhadap kaum perempuan dan rakyat tertindas dalam memperjuangkan penghapusan kekerasan seksual.

Kami melihat bahwa kritik Marx terhadap masyarakat kapitalis dan ramalannya mengenai perkembangan masa depannya menjadi sasaran banyak kritik. Salah satu kritik yaitu reaksi terhadap Marxisme sebagai satu ideologi politik, bukan sebagai suatu teori sosiologi atau teori ekonomi yang objektif. Secara umum kritik-kritik terhadap interpretasi Marxis mengenai masyarakat kapitalis mengemukan bahwa Marx meremehkan fleksibilitas dan kemampuan menyesuaikan diri dari masyarakat kapitalis dalam menyelesaikan krisis. Namun, Marx melihat bahwa proses dominasi atau kekuasaan yang terjadi selalu dilakukan dengan cara-cara fisikal melalui pemaksaan.

Pembagian kelas menurut Karl Marx tidak hanya tentang hierarki kedudukan seseorang secara ekonomi melainkan juga kedudukan seseorang dalam hierarki kekuasaan untuk mempertahankan kedudukanya dalam suatu kelas. Dasar Anggapan Marx tentang kelas sosial bahwa sebuah kelas sosial baru di anggap kelas dalam arti yang sebenarnya, apabila dia bukan hanya secara (objektif) merupakan golongan dengan kepentingan sendiri, melainkan juga sebagai (subjektif) menyadari sebagai kelas, sebagai golongan khusus yang mau memperjuangkannya. Pelaku utama dalam perubahan sosial bukanlah individu tertentu, tetapi kelas-kelas sosial. Bukan hanya kelas sosial apa yang ditemukan, tetapi struktur kekuasaan yang ada dalam kelas sosial tersebut. Dalam kelas-kelas ada yang berkuasa dan yang dikuasai.

Pertentangan antara kelas atas dan kelas bawah bukan karena adanya perasaan iri atau egois, tetapi karena adanya kepentingan yang obyektif. Menurut Marx, negara bukanlah lembaga yang mengatur kesejahteraan rakyatnya, tetapi sebagai alat untuk mengamankan orang-orang dari kelas atas. Jadi negara tidak netral, tetapi selalu berpihak kepada kelas atas, maka kebijakan yang dibuat oleh negara lebih menguntungkan kelas atas. Pelaku utama dalam 
perubahan sosial bukanlah individu tertentu, tetapi kelas-kelas sosial. Bukan hanya kelas sosial apa yang ditemukan, tetapi struktur kekuasaan yang ada dalam kelas sosial tersebut.

Salah satu pemikiran yang mempunyai pengaruh besar terhadap perkembangan teori konflik adalah analisis Marx tentang konflik yang menyatakan bahwa konflik utama yang terjadi dimasyarakat adalah konflik antar kelas (Haryanto, 2016). Dalam Pandangan Karl Marx, sejarah sosial menurutnya merupakan sejarah perjuangan kelas dalam social movement (Cox, 2015). Setiap tipe masyarakat selalu terdapat didalamnya dua kelas yang saling berbeda kepentinganya secara diametrical, sehingga menimbulkan konflik diantara keduanya. Teori konflik Karl Marx tertarik pada bagaimana kelas yang memiliki kekuasaan berusaha mengontrol kelas yang tidak memiliki kekuasaan. Konflik merupakan unsur utama dalam politik dan perubahan sosial. Teoritikus konflik tidak membatasi perhatianya pada tindakan konflik kekerasan. Mereka jugs tertarik pada kompetisi non kekerasan Antar kelompok dalam masyarakat, antar laki-laki dan perempuan, ras, antar generasi dan latar belakang nasional (Haryanto, 2016).

\section{METODE PENELITIAN}

Paper ini menggunakan jenis metode penelitian kualitatif deskriptif dengan pendekatan kajian pustaka. Desk review dilakukan oleh setiap penulis dengan menggunakan tools penelusuran pada repositori daring (online). Data dalam penelitian ini menggunakan data sekunder. Eksplorasi data sekunder didapatkan melalui penelusuran tulisan-tulisan ilmiah dan populer seperti jurnal, tulisan di koran, media daring dan buku yang terkait dengan tema pengesahan RUU Penghapusan Kekerasan Seksual dan ide-ide pokok teori Karl Marx tentang perjuangan kelas dan gerakan sosial serta melalui dokumen pemerintahan Indonesia seperti draft RUU Penghapusan Kekerasan Seksual dan naskah akademik RUU Penghapusan Kekerasan Seksual.

Pengumpulan data melalui penelusuran repositori daring yaitu: Google Scholar, Elsevier, dan J-STOR. Data yang terkumpul kemudian di kategorisasi berdasarkan tema, dimana masing-masing penulis mendapatkan penugasan dalam menelusuri literatur; Nikodemus Niko menelusuri literatur dengan kata kunci Teori Kelas dan social movement 
Karl Marx, Atem mendapatkan penugasan menelusuri literatur dengan kata kunci RUU Penghapusan Kekerasan Seksual, Alif Alfi Syahrin mendapatkan penugasan menelusuri literatur tentang aksi demonstrasi dalam upaya pengesahan RUU Penghapusan Kekerasan Seksual, Alvin Dwi Rahmawan mendapatkan penugasan penelusuran kata kunci kasuskasus kekerasan seksual di Indonesia, dan Anggi Mardiana mendapatkan penugasan penelusuran kata kunci pemikiran Marx tentang organisasi politik dan power. Hasil desk review masing-masing penulis kemudian didiskusikan bersama-sama.

Analisis data dilakukan pada saat yang bersamaan dengan penulisan paper ini, sehingga verifikasi data dilakukan pada saat yang bersamaan. Artinya bahwa setiap penulis memvalidasi data hasil penelusurannya pada saat bersamaan dengan penulisan sesuai dengan penugasan.

\section{PEMBAHASAN}

\section{Gejolak (Pro-Kontra) RUU Penghapusan Kekerasan seksual.}

Problema hukum tehadap kejahatan seksual di Indonesia masih belum menemukan benang merah, yang mana saat ini Indonesia dalam kondisi darurat masalah kekerasan seksual. Kasus kekerasan terhadap perempuan ini merupakan fenomena gunung es, yang mana hanya sebagian kasus-kasus yang dilaporkan dan banyak kasus yang tidak diungkapkan. Hal ini yang mendasari agar RUU Penghapusan Kekerasan Seksual dimasukan ke dalam legislasi nasional dan prolegnas prioritas.

Rancangan Undang-Undang Penghapusan Kekerasan Seksual (RUU PKS) beberapa tahun terakhir diekspektasikan sebagai payung hukum yang akan diandalkan sebagai bentuk penyempurnaan hukum yang mengatur kekerasan seksual, dalam KUHP dalam pasal 285 sampai 288 hanya mengatur tindak kejahatan perkosaan dan dalam rumusannya belum mampu melindungi korban dari kekerasan. Namun demikian RUU PKS nyatanya mandek dalam pusaran parlemen dan perpolitikan. RUU PKS ini memunculkan pro dan kontra baik dikalangan masyarakat, partai politik, akademisi dan Lembaga-lembaga terkait. Di dalam parlemen fraksi partai politik terbagi menjadi dua kubu yakni kubu yang mendukung di sahkannya RUU PKS dan kubu yang menentang. 
Beberapa fraksi partai politik masing masing beradu argument terkait pasal-pasal yang terdapat dalam RUU PKS tersebut. Setidaknya ada beberapa hal yang menimbulkan pro dan kontra, yakni mulai dari judul yang dinilai bermasalah karena memilih kata kekerasan seksual yang dianggap problematis dan akan mempengaruhi substansi isi RUU tersebut. RUU Penghapusan Kekerasan Seksual juga dituding melegalkan zina atau seks bebas, aborsi, pro LGBT, lalu tindakan non fisik seperti siulan, kedipan mata juga bisa dipidana, dan tokoh agama yang melakjukan pelecehan akan mendapatkan tambahan hukuman (news.detik.com, 2019).

Mengacu pada naskah akademik Rancangan Undang-Undang Tentang Penghapusan Kekerasan Seksual pasal 1 (1) kekerasan seksual adalah setiap perbuatan merendahkan menghina, menyerang dan/atau tindakan lainnya, terhadap tubuh yang terkait dengan nafsu perkelaminan, hasrat seksual seseorang, dan/atau fungsi reproduksi, secara paksa, bertentangan dengan kehendak seseorang, dan/atau tindakan lain yang menyebabkan seseorang itu tidak mampu memberikan persetujuan dalam keadaan bebas, karena ketimpangan relasi kuasa, relasi gender dan/atau sebab lain, yang berakibat atau dapat berakibat penderitaan atau kesengsaraan terhadap secara fisik, psikis, seksual, kerugian secara ekonomi, sosial, budaya, dan/atau politik.

Penafsiran isi dari pasal-pasal tersebut menimbulkan perdebatan. Beberapa pihak yang menolak pengesahan ini seperti Profesor Euis Sunarti Guru Besar Institute Pertanian Bogor (IPB), Wakil Sektretaris Jendral Majelis Ulama Indonesia (MUI) yakni Tengku Zulkarnain, serta Fraksi Partai Keadilan Sejahtera (P-KS). Ketua praksi P-KS Jazuli Juwaini menyampaikan penolakannya terhadap RUU Penghapusan Kekerasan Seksual karena dianggap akan menimbulkan polemik di masyarakat dan bertentangan dengan nilai-nilai Pancasila dan Agama. Sama halnya diutarakan oleh dosen Universitas Padjadjaran Maimon Herawati yang menganggap RUU Penghapusan Kekerasan Seksual ini pro zina dan memiliki sudut pandang barat dan kalimat-kalimatnya mengandung multitafsir.

Sebaliknya Masruchah, Ketua Sub Komisi Pendidikan Komnas Perempuan merespon penolakan fraksi Partai Keadilan Sejahtera tersebut sebagai bentuk inkonsisten fraksi partai politik, karena sebelumnya semua fraksi menyetujui saat RUU tersebut diusulkan dan dibahas dalam Badan Legislasi (Baleg) DPR (Erdianto, 2019). Hal ini di dukung fraksi Partai Demokrasi Indonesia Perjuangan (PDIP), Diah Pitaloka selaku Anggota Komisi VIII DPR RI 
berpendapat bahwa sering terjadi kasus kekerasan seksual yang sulit dibuktikan, oleh karennya korban tidak mendapatkan keadilan dan justru menjadi korban hukum. Hal tersebut terjadi karena tidak adanya instrument hukum yang dengan jelas mengatur jenis-jenis kekerasan seksual secara menyeluruh. Hal senada di sampaikan oleh) Siti Mazumah selaku Direktur LBH Asosiasi Perempuan Indonesia untuk Keadilan (LBH APIK) yang berharap agar, RUU penghapusan kekerasan seksual segera di sahkan (Ramadhan, 2019).

Adapun kelompok yang masih menolak RUU penghapusan kekerasan seksual melalui petisi online ini, menganggap RUU Penghapusan Kekerasan Seksual pro zina, pro LGBT dimana LGBT dinilai akan berkembang karna dilindungi RUU PKS, pro aborsi yang dimana sudah jelas ada Undang-Undang kesehatan Nomor 36 Tahun 2009 Tentang Kesehatan, perbedaan pandangan antar kelompok maupun kelas terjadi karena belum sampai pada satu kesepahaman tujuan. Salah satu pertimbangan dalam pengesahan RUU PKS ini ialah kelompok rentan yang rentan terjerat (LGBT) yang diluar keinginannya sendiri (faktor gen) dinilai rentan terjerat.

Selama tidak ada undang-undang yang mengaturnya, LGBT tidak dapat dipidanakan dan hakim memiliki pertimbangan dalam memutus suatu perkara dengan melihat kembali pada naskah akademik sebagai bahan pertimbangan. Yang terjadi sekarang para pembuat kebijakan terlalu berlarut-larut dalam menganalisa dugaan-dugaan yang justru bertolak belakang dengan substansi RUU Penghapusan kekerasan seksual, misal dugaan pro zina karena belum ada perluasan pasal KUHP yang mengatur tentang zina bagi mereka yang belum menikah, akan tetapi hal ini jelas berbeda dengan substansi RUU Pengahapusan Kekerasan Seksual. RUU Penghapusan Kekerasan Seksual perlu segera disahkan karena Indonesia saat ini Darurat Kekerasan Seksual. Gejayan memanggil merupakan sarana perjuangan kelas yang perlu segera dipertimbangan para penguasa, karena kepentingsn gejayan memanggi ialah murni untuk kepentingan rakyat pada umumnya yang belum bercampur dengan kedudukan, kekuasaan dan kepentingan.

Gejolak pro dan kontra ini juga mucul dikalangan mayarakat luas termasuk dikalangan mahasiswa dan aktivis, yang menuntut untuk disegerakan pengesahan RUU PKS, selain itu perdebatan yang tak terkoordinir juga menyebar di sosial-media, pada akhirnya perdebatan 
berbagai pihak ini berada di jalan buntu, karena keputusan berada di tangan pemangku kebijakan. Polemik pro dan kontra terkait pengesahaan RUU penghapusan kekerasan seksual ini bermuara pada tertundanya RUU tersebut, dan belum lama ini, masyarakat kembali dikejutkan dengan adanya RUU Ketahanan keluarga yang menambah gejolak baru, dan semakin mengaburkan RUU PKS yang seharusnya menjadi konsen pemerintah untuk segera di selesaikan dalam tataran pengambilan keputusan.

\section{Perjuangan Kelas: Aksi Pendesakan Pengesahan RUU Penghapusan Kekerasan Seksual}

Perempuan di Indonesia masih rentan terhadap kekerasan yang dikarenakan budaya patriaki. Seperti yang dikemukan oleh Purwanti (2017) bahwa budaya patriarki ini adalah perspektif yang menyatakan bahwa laki-laki mendominasi semua peran dalam sistem sosial; karena perempuan diabaikan dari peran yang juga bisa mereka lakukan seperti laki-laki. Peran sosial ini termasuk dalam aspek sosial, agama, ekonomi, politik, atau budaya. Hal inilah menjadi salah satu faktor rentannya kekerasan yang dialami oleh kaum perempuan di Indonesia. Sehingga salah satu aksi yang bermunculan mengenai tuntutan disahkannya RUU PKS memiliki tujuan untuk memperjelas posisi kaum perempuan maupun korban pelecehan seksual dalam sudut pandang hukum yang adil. Framing ini penting untuk memunculkan rasa kebersamaan dalam aksi/movement (Arnold \& Ake, 2013).

Kekerasan terhadap perempuan mencakup pelecehan fisik, seksual, psikologis, dan ekonomi, serta pemotongan melintasi batas usia, ras, budaya, kekayaan, dan geografi (Nilan, dkk, 2014). Begitu juga berdasarkan Pasal 11 ayat (1) menyatakan kekerasan seksual terdiri dari: pelecehan seksual; eksploitasi seksual; pemaksaan kontrasepsi; pemaksaan aborsi; perkosaan; pemaksaan perkawinan; pemaksaan pelacuran; perbudakan seksual; dan penyiksaan seksual (Movanita, 2019a).

Tuntutan untuk disahkannya RUU PKS dikarenakan bahwa "salah satu permasalahan yang dihadapi terkait peraturan-peraturan perundang-undangan mengenai kekerasan seksual di Indonesia adalah bahwa ketentuan-ketentuan ini masih diatur dalam peraturan-peraturan yang terpisah dan di Indonesia belum ada suatu peraturan perundang-undangan yang mengatur tentang kekerasan seksual secara spesifik" (Kusuma, dkk., 2019). Terlebih khususnya 
perempuan yang menjadi korban telah menduduki posisi yang lebih rumit terkait dengan beban sosial mereka (Purwanti dan Prabowo, 2018). Hal ini semakin diperjelas bahwa budaya patriarkal sudah mengakar dalam kehidupan masyarakat Indonesia (Purwanti, 2017). Sehingga perlu adanya UU yang lebih spesifik mengatur tentang kekerasan seksual.

Aksi-aksi yang bermunculan mengenai tuntutan disahkannya RUU PKS merupakan gambaran kekecawaan atas respon pemerintah yang dinilai lamban dalam mengesahkan suatu UU. Padahal Rancangan Undang-Undang tentang Penghapusan Kekerasan Seksual (RUUPKS) merupakan suatu upaya pembaruan hukum dalam mengatasi berbagai persoalan terkait kekerasan seksual (Kusuma, dkk., 2019). Lebih lanjut, Kusuma, dkk menyebutkan bahwa pembaharuan dalam bentuk hukum ini memiliki tujuan sebagai berikut: melakukan pencegahan terhadap terjadinya peristiwa kekerasan seksual, mengembangkan dan melaksanakan mekanisme penanganan, perlindungan, dan pemulihan yang melibatkan masyarakat dan berpihak pada korban, agar Korban dapat melampaui kekerasan yang ia alami dan menjadi seorang penyintas dan memberikan keadilan bagi korban kejahatan seksual, melalui pidana dan tindakan tegas bagi pelaku kekerasan seksual.

Pada fenomena sosial, tentunya tak dapat dihindarkan dengan sebuah aksi yang dilakukan oleh sekelompok masyarakat. Terlebih menyangkut dengan khalayak umum. Seperti yang diungkapkan oleh Winarno (2019) bahwa serangkaian demonstrasi yang terjadi bertujuan menggugat rezim penguasa yang tak berpihak pada rakyat. Sebuah aksi yang mencuat di khalayak ramai merupakan sebuah simbol perjuangan dalam menyampaikan aspirasi serta pembelaan terhadap kaum tertindas. Salah satunya kaum perempuan di Indonesia yang rentan mengalami kekerasan, dalam hal ini adalah kaum tertindas.

Pembagian yang paling mendasar dan penting dalam masyarakat adalah pembagian antara kelas-kelas yang berbeda. Marx menegaskan bahwa dia melihat kelas sosial sebagai kategori yang paling dasar dalam struktur sosial (Upe, 2010). Bagaimana kelas-kelas itu muncul? Pertanyaan ini sangat erat kaitannya dengan dengan konsep Marx mengenai materialisme historis. Penegasan ini yaitu kemampuan manusia untuk memenuhi pelbagai kebutuhannya, bergantung pada keterlibatannya dalam hubungan sosial dengan orang lain untuk mengubah lingkungan materil melalui kegiatan-kegiatan produktif. 
Perihal wacana pengesahan Rancangan Undang-Undang Penghapusan Kekerasan Seksual (RUU PKS) menimbulkan sejumlah aksi demonstrasi yang membagi dua buah kubu antara pro RUU PKS dan kontra RUU PKS. Seperti contoh ada anggapan yang mengatakan bahwa RUU PKS secara tidak langsung dapat memberikan pelegalan seks diluar nikah (zina), padahal tentang zina sudah diatur dalam KUHP (Andriasari, 2019). Aksi yang timbul di kalangan masyarakat, khususnya dari kelompok mahasiswa, menunjukkan bahwa wacana pengesahan RUU PKS dapat menghadirkan berbagai macam aspirasi. Hal ini dikarenakan terdapat berbagai macam penafsiran serta pandangan ke depan mengenai RUU PKS, baik akan disahkan atau bahkan dibatalkan.

Aksi \#GejayanMemanggil merupakan bentuk aksi yang dimotori oleh mahasiswamahasiswa di Yogyakarta dengan mengedepankan seruan damai untuk kesejahteraan dan kebebasan yang dianggap semakin hari semakin dibatasi (Sukendar, 2019). Terdapat salah satu butir tuntutan dalam aksi gejayan memanggil yakni menuntut pengesahan RUU PKS yang dianggap sudah terlalu lama dibahas sejak 2017 (Movanita, 2019b). Dengan maksud memberikan payung hukum terhadap korban-korban pelecahan seksual. Namun, terdapat anggapan dari kelompok yang menolak untuk disahkannya RUU PKS, seperti yang dikutip pernyataan Rita Soebagio selaku Ketua Umum AILA yang dilansir dalam AyoBandung.com (2019) bahwa dalam pengesahan RUU PKS terdapat kelompok-kelompok yang berpaham kebebasan seksual. Sehingga mengindikasikan memberi izin kebebasan seksual yang tak sesuai dengan adat ketimuran. Padahal penafsiran tersebut kurang tepat jika ditelusuri lebih mendalam.

Walaupun tidak secara gamblang Marx mendefinisikan kelas sosial tentu kita dapat mengetahui bahwa kelas sosial adalah golongan dalam stuktur sosial. Tetapi, dalam pemikiran Marx dapat diindikasikan bahwa kelas sosial merupakan gejala khas masyarakat pascafeodal. Kelas sosial dalam pandangan Marx yakni kelas pekerja atau kelas bawah (ploletar) dan juga pemilik modal atau kelas atas (borjuis). Kedua kelas ini selalu mengalami pertentangan, pertentangan mereka bukan karena buruh iri atau para majikan egois, melainkan karena kepentingan dua kelas itu secara objektif berlawanan satu sama lain (Suseno, 2016). Atas konsepnya itu, dalam sistem yang dikemukan Marx bahwa negara secara hakiki merupakan 
negara kelas, artinya secara tidak langsung negara dikuasai oleh kelas-kelas tertentu yang memiliki kekuasaan baik dibidang ekonomi dan politik.

Analisis Marx mengenai kesadaran kelas tertindas sangat penting untuk melakukan sebuah gerakan sosial. Kesadaran kolektif yang melahirkan gerakan sosial dan bertujuan memperjuangkan kelas tertindas. Perjuanagan kelas diperuntukkan agar adanya bargaining position sehingga kesenjangan antara kelas atas dengan kelas bawah semakin hilang dan mencapai harapan yaitu masyarakat tanpa kelas. Seperti yang dikatakan oleh Marx jika ingin terbebas keterasingan dan penindasan maka lakukan gerakan perjuangan kelas. Apa yang dikatakan Marx sangat sejalan dengan apa yang dilakukan oleh masyarakat pada dewasa ini, pergerakan-pergerakan perjuangan kelas yang rata-rata banyak dilakukan oleh masyarakat biasa kepada penguasa.

Jika di Jerman dalam bukunya "Manifesto Komunis" Marx dan Angels mengatakan bahwa perjuangan kelas yang dilakukan yaitu untuk melawan bentuk penindasan yang dilakukan oleh kelas borjuis dan pemerintah. Maka di Indonesia spirit perjuangan kelas itu diadopsi oleh gerakan perempuan dan dalam beberapa bentuk gerakan-gerakan rakyat. Semangat yang dikemukan oleh Marx mengenai perjuangan kelas memicu gejolak pergerakan kelas-kelas tertindas lainnya. Seperti halnya untuk mencapai disahkannya Rancangan Undangundang Penghapusan Kekerasan Seksual (RUU PKS) maka perlunya gerakan perjuangan kelas dari masyarakat, terutama kelas-kelas yang dalam hal ini memiliki kerentanan menjadi korban kekerasan seksual, jika rancangan ini tidak kunjung disahkan.

Perjuangan kelas dalam upaya pengesahan RUU Penghapusan kekerasan seksual ini memerlukan adanya kesadaran kelas. Kesadaran kelas apa yang dimaksud? Dalam analisis Marx, kesadaran kelas yang dimaksud adalah kesadaran kelas para pekerja atau buruh yang bekerja bersama-sama di suatu pabrik dengan dalam kondisi yang kurang manusiawi dan hidup berdampingan satu sama lain (antar buruh satu pabrik) sebagai tetangga di satu kota juga, kaum proletar menjadi sadar akan penderitaan bersama dan kemelaratan ekonominya. Singkatnya, terpusatnya mereka pada satu tempat memungkinkan terbentuknya jaringan komunikasi dan menghasilkan kesadaran bersama (Umanailo, 2019). Tetapi jika dilihat dalam konteks perjuangan untuk mengesahkan RUU Penghapusan Kekerasan seksual ini perlu adanya 
kesadaran kelas dari golongan kelas rakyat yang merasa peduli terhadap bentuk-bentuk kekerasan seksual, sehingga dari kesadaran kelas itu lahirlah perjuangan kelas.

Perjuangan kelas yang sangat aktif digulirkan beberapa tahun terakhir ini menuntut penguasa (negara) segera mengesahkan rancangan undang-undang penghapusan kekerasan seksual (RUU PKS). Seperti halnya gerakan Gejayan Memanggil, Rakyat Gugat Negara, Gerakan Umat Lintas Iman Se-Jawa Barat (Geulis) dan aksi lainnya yang menuntut hadirnya negara dalam penanganan kasus kekerasan seksual di Indonesia. Asumsi utama yang menggerakkan gerakan itu karena melihat fenomena-fenomena kekerasan seksual yang setiap tahunnya selalu mengalami peningkatan. Berdasarkan data dari Komnas Perempuan bahwa masih banyak kekerasan seksual yang dilakukan baik di ranah personal maupun di ranah publik.

Gejayan memanggil merupakan bentuk perjuangan kelas dari mahasiswa sebagai agent of change yang merupakan bagian dari civil society sebagai pengontrol para pembuat kebijakan yang dinilai netral, garda terdepan dalam memperjuangkan kepentingan masyarakat yang kerap merasa terabaikan dengan adanya kepentingan para penguasa. Salah satu tuntutan "gejayan memanggil” ialah sahkan RUU Penghapusan Kekerasan Seksual, yang bukan hanya menjadi jalan bagi perempuan mendapatkan ruang aman dan keadilan, tetapi juga menjadi sumber movement dan keberdayaan perempuan (Ogato, 2013).

\section{KESIMPULAN}

Gerakan perjuangan kelas dalam upaya pengesahan RUU penghapusan kekerasan seksual tergambarkan dalam bentuk aksi-aksi di berbagai wilayah di Indonesia. Gerakan kolektif seperti Gejayan memanngil, Rakyat Gugat Negara, Gerakan Umat Lintas Iman SeJawa Barat (Geulis) adalah bentuk dari perjuangan kelas, yang di dalamnya terdapat kaum perempuan. Dalam hal ini, kelas yang tidak memiliki kekuasaan membentuk aksi kolektif untuk menuntut kelas penguasa agar mengesahkan RUU Penghapusan Kekerasan Seksual. Kami memahami narasi kelas yang digaungkan Karl Marx pada akhirnya membentuk suatu relasi kolektif. Artinya bahwa movement yang dilakukan terhadap perjuangan pengesahan 
RUU Penghapusan Kekerasan Seksual ini tidak hanya berasal dari satu kelas tertentu dan gender tertentu, melainkan membentuk kolektifitas. Kolektif dalam hal ini adalah bagi siapasaja (kalangan) yang mendesak pengesahan RUU ini untuk segera disahkan, dengan pengharapan akan terdapat perbaikan sistem hukum negara dalam penanganan kekerasan seksual, baik penanganan hak-hak korban maupun penghukuman bagi pelaku.

\section{DAFTAR PUSTAKA}

. (2019). Naskah Akademik Rancangan Undang-Undang Penghapusan Kekerasan Seksual. Diakses dari: https://www.komnasperempuan.go.id/read-news-naskahakademik-rancangan-undang-undang-tentang-penghapusan-kekerasan-seksual

Adam, A. (2019, 22 Februari). Pelecehan Seksual di Kantor dan Beban Ganda Pekerja Perempuan. Diakses dari: https://tirto.id/pelecehan-seksual-di-kantor-dan-beban-gandapekerja-perempuan-dhxM

Aktar, S. (2019). Transnational feminism and women's activism: Strategies for engagement and empowerment in Bangladesh. Asian Journal of Women's Studies. 25(2):285-294. Doi: https://doi.org/10.1080/12259276.2019.1612508

Andriasari, D. (2019). Woman's Day Vs RUU P-Kekerasan Seksual. Harian Pikiran Rakyat. Edisi Jum'at 8 Maret 2019.

Arnold, G., \& Ake, J. (2013). Reframing the Narrative of the Battered Women's Movement. Violence Against Women. 19(5):557-578. Doi: https://doi.org/10.1177/1077801213490508

AyoBandung.com. AILA Tegaskan Tolak RUU Penghapusan Kekerasan Seksual. Diakses pada Januari 22, 2020, dari: https://www.ayobandung.com/read/2019/09/25/64859/ailategaskan-tolak-ruu-penghapusan-kekerasan-seksual 
Baker, C. N., \& Bevacqua, M. (2017). Challenging Narratives of the Anti-Rape Movement's Decline. Violence Against Women. 24(3)1-27. Doi: https://doi.org/10.1177/1077801216689164

Barker, et al. (Ed). (2013). Marxism and Social Movement. Leiden \& Boston: Koninklijke Brill NV.

Basile, K. C., \& Smith, S. G. (2011). Sexual Violence Victimization of Women: Prevalence, Characteristics, and the Role of Public Health and Prevention. American Journal of Lifestyle Medicine. Doi: 10.1177/1559827611409512

Basir \& Ismail. (2012). Karl Marx dan Konsep Perjuangan Kelas Sosial. International Journal of Islamic Thought. 1: 27-33. Doi: 10.24035/ijit.01.2012.004

Bayeh, E. (2016). The role of empowering women and achieving gender equality to the sustainable development of Ethiopia. Pacific Science Review B: Humanities and Social Science. Doi: https://doi.org/10.1016/j.psrb.2016.09.013

Berberoglu, B. (2018). The Marxist Theory of Social Movement, Revolution, and Social Transformation. In Berberoglu, B. (eds). The Palgrave Handbook of Social Movementts, Revolution, and Social Transformation. Palgrave Macmillan, Cham. Doi: https://doi.org/10.1007/978-3-319-92354-3_4

Coburn, E. (2016). Marxism and Social Movements. Socialist Studies/Études socialistes. 11(1):237-250.

Cox, L. (2015, March 16). Thinking Marxism and Social Movements. Diakses dari: https://www.ppesydney.net/thinking-marxism-and-social-movements/

Cripps, J., \& Stermac, L. (2018). Cyber-Sexual Violence and Negative Emotional States among Women in a Canadian University. International Journal of Cyber Criminology. 12(1):171-186. 
Devi, T. R. (2017). Gender Equality: Women Empowerment. Global Journal for Research Analysis. 6(9):141-143.

Dewantara, J. R. (2020, 14 Januari). Perempuan dan Anak Kekerasan Seksual di Kulonprogo Mulai Sadar untuk Lapor. Diakses dari: https://jogjapolitan.harianjogja.com/read/2020/01/14/514/1029366/perempuan-dananak-korban-kekerasan-di-kulonprogo-mulai-sadar-untuk-lapor

Erdianto, K. (2019, 30 Juli). Fraksi yang Menolak Pengesahan RUU PKS Dinilai Tidak Konsisten. Diakses dari: https://nasional.kompas.com/read/2019/07/30/18285971/fraksi-yang-menolakpengesahan-ruu-pks-dinilai-tidak-konsisten?page $=$ all

Garcia-Moreno, C., \& Amin, A. (2019). Violence Against Women: where are we 25 years after ICPD and where do we need to go? Sexual and Reproductive Health Matters. 27(1):346348. Doi: https://doi.org/10.1080/26410397.2019.1676533

Guruge, S., Roche, B., \& Catallo, C. (2012). Violence against Women: An Exploration of the Physical and Mental Health Trends among Immigrant and Refugee Women in Canada. Nursing Research and Practice. Doi: 10.1155/2012/434592

Haryanto, S. (2012). Spektrum Teori Sosial. Jogjakarta: Ar-Ruzz Media.

Hukum Online. Isu RUU Penghapusan Kekerasan Seksual Versi Komnas Perempuan. Diakses pada $\quad$ Maret 2020, dari: https://www.hukumonline.com/berita/baca/lt5733216560b1b/ini-isi-ruu-penghapusankekerasan-seksual-versi-komnas-perempuan/

Komnas Perempuan. (2013). Korban Berjuang, Publik Bergerak: Mendobrak Stagnansi Sistem Hukum: Catatan Tahunan Komnas Perempuan 2012. Diakses dari: http://www.komnasperempuan.go.id/wp-content/uploads/2013/12/CatatanTahunanKomnas-Perempuan-2012.pdf 
Komnas Perempuan. (2019). Lembar Fakta dan Poin Kunci Catatan Tahunan Komnas Perempuan Tahun 2019. Diakses dari: https://www.komnasperempuan.go.id/read-newslembar-fakta-dan-poin-kunci-catatan-tahunan-komnas-perempuan-tahun-2019

Kusuma, A, dkk. (2019). Analisis Keberlakuan RKUHP dan RUU-PKS dalam Mengatur Tindak Kekerasan Seksual. Lex Scientia Law Review. 2(2):55-68.

Levine, E. C. (2017). Sexual Script and Criminal Statutes: Gender Restictions, Spousal Allowences, and Victim Accountability After Rape Law Reform. Violence Against Women. 24(3):1-28. Doi: https://doi.org/10.1177/1077801216687876

Lin, Z., \& Yang, L. (2019). Indivudual and collective empowerment: Women's voices in the \#MeToo movement in China. Asian Journal of Women's Studies. 25(2):117-131. Doi: https://doi.org/10.1080/12259276.2019.1573002

Martinez, M. A. (2017, August 27). A Marxist Approach to Social Movements? Retrieved from: http://www.miguelangelmartinez.net/?2017-A-Marxist-Approach-to-Social

Movanita, A. N. K. (2019a), September 23). Kekeliruan Memahami RUU PKS, Dianggap Liberal dan Tak Sesuai Agama. Diakses dari: https://nasional.kompas.com/read/2019/09/23/19350151/kekeliruan-memahami-ruupks-dianggap-liberal-dan-tak-sesuai-agama?page=all

Movanita, A. N. K. (2019b), September 24). Ramai-ramai Turun ke Jalan, Apa yang Dituntut Mahasiswa? Diakses dari: https://nasional.kompas.com/read/2019/09/24/15440851/ramai-ramai-turun-ke-jalanapa-yang-dituntut-mahasiswa?page $=$ all

Moyo, T., \& Dhliwayo, R. (2019). Archieving Gender Equality and Women's Empowerment in Sub-Saharan Africa: Lessons from the Experience of Selected Countries. Journal of Developing Societies. 35(2): Doi: https://doi.org/10.1177/0169796X19845957 
Never Okay Project. (2018). Kondisi Pelecehan Seksual di Tempat Kerja. Diakses pada Maret

24, 2020, dari: https://neverokayproject.org/wp-content/uploads/2019/12/SurveiPelecehan-Seksual-di-Tempat-Kerja-Never-Okay-Project-2018-4.pdf

News.detik.com. Pro-Kontra RUU P-KS Anda Mendukung atau Menolak. Diakses pada Maret 22, 2020, dari: https://news.detik.com/pro-kontra/d-4728479/kontroversi-ruu-p-ks-andamendukung-atau-menolak

Niko, N., \& Rahmawan, A. D. (2020). Supremasi Patriarki: Reaksi Masyarakat Indonesia dalam Menyikapi Narasi Seksualitas dan Perkosaan Kasus Reynhard Sinaga. Jurnal Analisa Sosiologi. 9(1):137-152.

Nilan, P., Demartoto, A., Broom, A., \& Germov, J. (2014). Indonesian Men's Perceptions of Violence Against Women. Violence Against Women. 20(7): 869-888. Doi: $10.1177 / 1077801214543383$

Ogato, G. S. (2013). The quest for gender equality and women's empowerment in least developed countries: Policy and strategy implications for achieving millennium development goals in Ethiopia. International Journal of Sociology and Anthropology. 5(9):358-372. Doi: 10.5897/IJSA2013.0454

Purwanti, A. (2017). Protection and Rehabilitation for Women Victims of Violence according to Indonesian Law (Study on Central Java Government's handling through KPK2BGA). Diponegoro Law Review. 2(2):312-325. Doi: https://doi.org/10.14710/dilrev.2.2.2017.68-81

Purwanti, A., \& Prabowo, R. A. (2018). Women Rights Fulfillment As The Victim Of Gross Human Rights Violation: Urgency For The Sexual Violence Eradication Bill. Indonesia Law Review. (3):303-315. Doi: http://dx.doi.org/10.15742/ilrev.v8n3.509

Setiadi, E. M., \& Kolip, U. (2011). Pengantar Sosiologi Pemahaman Fakta dan Gejala Permasalahan Sosial. Jakarta: Prenada Media Group. 
Sovann, R. (2019). Good practices for eliminating violence against women in Cambodia. Asian Journal of Women's Studies. 25(2):295-307. Doi: https://doi.org/10.1080/12259276.2019.1615242

Sukendar, M. U. (2019). Konstruksi Realitas Berita \#Gejayan Memanggil 23 September 2019 dalam Media Online Detik.com dan Kompas.com. Indonusa Conference on Technology and Social Science.

Suseno, F. M. (2016). Pemikiran Karl Marx Dari Sosialisme Utopis ke Perselisihan Revisionisme, cetakan ke-sepuluh. Jakarta: PT Gramedia Pustaka Utama.

Umanailo, C. B. (2019). Pemikiran-pemikiran Karl Marx. Doi: 10.31219/osf.io/5q2ts. Diakses dari: https://www.researchgate.net/publication/336764610

Upe, A. (2010). Tradisi Aliran Dalam Sosiologi Dari Filosofi Positivistik ke Post Positivistik. Jakarta: PT RajaGrafindo persaja.

Wariyatun. (2019). Creating zero tolerence for violence against women. Asian Journal of Women's Studies. 25(2):459-467. Doi: https://doi.org/10.1080/12259276.2019.1638047

Winarno, S. (2019). Demokrasi, Demonstrasi dan Demo Crazy. Malang Post. Edisi 25 September 2019. 